Int. J. Electrochem. Sci., 1(2006)92-98

International Journal of

ELECTROCHEMICAL

SCIENCE

www.electrochemsci.org

\title{
The inhibition of steel corrosion in hydrochloric acid solution by juice of Prunus cerasus
}

\author{
H. Ashassi-Sorkhabi ${ }^{1 *}$, D. Seifzadeh ${ }^{1}$, \\ ${ }^{1}$ Electrochemistry Research Lab, Physical Chemistry Department, Faculty of Chemistry, University of \\ Tabriz, Tabriz-Iran \\ *E-mail: habib_ashassi@yahoo.com \& $\underline{\text { ashassi@ tabrizu.ac.ir }}$
}

Received: 1 May 2006 / Accepted: 12 May 2006 / Published: 27 May 2006

Prunus cerasus juice inhibition effects on the corrosion of steel in hydrochloric acid $(\mathrm{HCl})$ solution were investigated using polarization and electrochemical impendence techniques. The results revealed that Prunus cerasus juice acts as a corrosion inhibitor in $\mathrm{HCl}$ solution. The inhibition efficiency increased with an increase in inhibitor concentration. The inhibition is attributed to adsorption of the inhibitor on the steel surface.

Keywords: Steel, Corrosion inhibition, Prunus cerasus, Electrochemical methods.

\section{INTRODUCTION}

Corrosion inhibitors are widely used in industry to reduce the corrosion rate of metals and alloys in contact with aggressive environments. Most of the corrosion inhibitors are synthetic chemicals, expensive, and very hazardous to environments. Therefore, it is desirable to source for environmetally safe inhibitors[1-3]. There are some reports on the inhibition effects of non-toxic compounds on the corrosion of metals. We have recently reported the inhibition effect of amino acids on the steel [1] and aluminum [4] corrosion in acidic media. The rare earth metals have been proposed as corrosion inhibitors [5-8]. The inhibition effects of some non-toxic organic compounds have been also reported for steel corrosion $[9,10]$ but they are expensive.

The aim of this study was to investigate the inhibition effect of Prunus cerasus juice as a cheap, raw and non-toxic corrosion inhibitor on steel corrosion in hydrochloric acid. The electrochemical measurements were used to evaluate the inhibition efficiencies. In addition, the effect of temperature on inhibition behavior of the inhibitor was also studied. 


\section{EXPERIMENTAL PART}

\subsection{Materials and samples}

Fully ripened Prunus cerasus were purchased from a local market (Tabriz, Iran). The fruits were washed in cold tap water and then mechanically compressed to obtain corresponding juice. The juice was then filtered to obtain a homogenous solution. In this process, we obtained $250 \mathrm{ml}$ Prunus cerasus juice from $0.5 \mathrm{Kg}$ fresh fruit. The extracted juice was kept frozen $\left(<0{ }^{\circ} \mathrm{C}\right)$ in glass bottles until further experiment. AR grade $\mathrm{HCl}$ ( $\mathrm{E}$ Merck) was used for preparing solutions. Double distilled water was used to prepare solution of $1 \mathrm{M} \mathrm{HCl}$ for this study. The concentrations of inhibitor were chosen as $0.3,0.6,1,2,3$ and $4 \mathrm{v} / \mathrm{v} \%$.

Commercially available St-37 steel was used as a working electrode specimen.

\section{2. Electrochemical measurements}

Electrochemical experiments were carried out using an Autolab, Potentiostat-Galvanostat (PGSTAT 30). A three-electrode arrangement was used for electrochemical studies. Working electrode was prepared from a St-37 steel sheet, mounted in polyester so that the area exposed to solution was 1 $\mathrm{cm}^{2}$. The specimens were polished with emery paper no. 400 to 1200 grade. They were cleaned with acetone, washed with double-distilled water, and finally dried at room temperature before being immersed in the acid solution. A saturated calomel electrode (SCE) and a platinum electrode (with approximately $1 \mathrm{~cm}^{2}$ surface area) were used as a reference and counter electrodes, respectively. For polarization measurements, the potential sweep rate was $1 \mathrm{mV} \mathrm{Sec}{ }^{-1}$. The immersion time before each measurement was $0.5 \mathrm{~h}$ to access an equilibrium potential. The impedance measurements were carried out in the frequency range of $10 \mathrm{kHz}$ to $10 \mathrm{mHz}$ at the open circuit potential, by applying $10 \mathrm{mV}$ sine wave ac voltage. The constant phase element $(C \mathrm{PE})$ and the charge transfer resistance $\left(R_{\mathrm{ct}}\right)$ were calculated from Nyquist plots as described elsewhere [11]. All experiments were performed at room temperature. In all experiments, the temperature of the solutions were controlled by using a Memert thermostat (Germany).

\section{RESULTS AND DISCUSSION}

\subsection{Linear polarization}

Linear polarization method was used to evaluate the corrosion rate of steel sample in the presence and absence of the juice. Linear polarization curves of steel in $1 \mathrm{M} \mathrm{HCl}$ solution with and without the juice are presented in Fig. 1. The electrochemical parameters: corrosion potential $\left(\mathrm{E}_{\mathrm{corr}}\right)$, corrosion current density $\left(\mathrm{I}_{\text {corr }}\right)$, anodic Tafel constant $\left(\mathrm{b}_{\mathrm{a}}\right)$ and cathodic Tafel constant $\left(\mathrm{b}_{\mathrm{c}}\right)$ were calculated using GPES software and are given in Table 1. The inhibition efficiencies were calculated, using the following equation [11]: 


$$
\mathbf{E} \%=\frac{\left(\mathbf{I}_{\text {sorr }}-\mathbf{I}_{\operatorname{corr}(\mathrm{inh})}\right)}{\mathbf{I}_{\mathrm{corr}}} \times \mathbf{1 0 0}
$$

Where the $\mathbf{I}_{\text {ocorr }}$ is the corrosion current density in the absence of inhibitor and the $\mathbf{I}_{\text {corr(inh) }}$ is the corrosion current density in the presence of inhibitor.

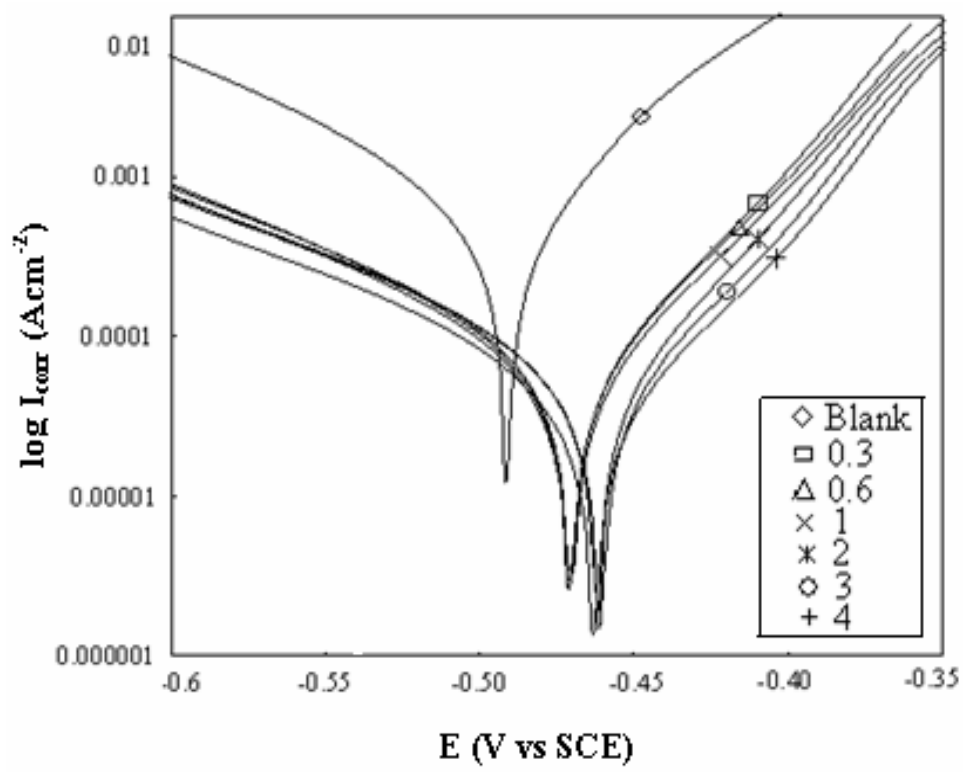

Figure 1. Linear polarization curves of steel corrosion in $1 \mathrm{M} \mathrm{HCl}$ solution with and without the juice at $25^{\circ} \mathrm{C}$.

Table 1. Corrosion parameters in the presence and absence of inhibitor obtained from polarization measurements.

\begin{tabular}{|c|c|c|c|c|c|c|}
\hline $\begin{array}{c}\text { Inhibitor } \\
\text { Concentration (v/v \%) }\end{array}$ & $\begin{array}{c}\mathbf{E}_{\mathbf{c o r r}} \\
\mathbf{( \mathbf { m V } )}\end{array}$ & $\begin{array}{c}\mathbf{R}_{\mathbf{p}} \\
\left(\mathbf{\Omega} \mathbf{~ c m}^{\mathbf{2}}\right)\end{array}$ & $\begin{array}{c}\mathbf{b}_{\mathbf{a}} \\
(\mathbf{m V} / \mathbf{d e c})\end{array}$ & $\begin{array}{c}\mathbf{b}_{\mathbf{c}} \\
(\mathbf{m V} / \mathbf{d e c})\end{array}$ & $\begin{array}{c}\mathbf{I}_{\mathbf{c o r r}} \\
\left(\mathbf{A c m}^{\mathbf{2}}\right)\end{array}$ & $\mathbf{I E \%}$ \\
\hline $\mathbf{0}$ & -480 & 31.4 & 65 & 100 & $5.46 \times 10^{-4}$ & - \\
\hline $\mathbf{0 . 3}$ & -470 & 266.0 & 56 & 94 & $5.75 \times 10^{-5}$ & 89.5 \\
\hline $\mathbf{0 . 6}$ & -471 & 313.3 & 58 & 92 & $4.93 \times 10^{-5}$ & 90.5 \\
\hline $\mathbf{1}$ & -473 & 320.5 & 56 & 90 & $4.6 \times 10^{-5}$ & 91.5 \\
\hline $\mathbf{2}$ & -462 & 330.3 & 53 & 91 & $4.41 \times 10^{-5}$ & 92.1 \\
\hline $\mathbf{3}$ & -459 & 369.8 & 58 & 89 & $4.11 \times 10^{-5}$ & 93.0 \\
\hline $\mathbf{4}$ & -461 & 471.7 & 62 & 92 & $3.39 \times 10^{-5}$ & 94.1 \\
\hline
\end{tabular}

It is clearly observed that the juice reduces the corrosion current density, and the suppression in current increases as the juice inhibitor concentration increases. Corrosion potential was shifted to the 
positive values in the presence of the juice, but has not been changed significantly with respect to inhibitor concentrations. Tafel slope values $b_{\mathrm{a}}$ and $b_{\mathrm{c}}$ were not with affected significantly in inhibited solution as compared to uninhibited solution. This observation suggests that inhibitor molecules adsorb on the metal surface by blocking the active sites on the metal surface [10]. The Prunus cerasus juice contains different organic compounds such as proteins, organic acids (such as ascorbic acid), vitamins, lipids, carbohydrates, pigments, and some inorganic ions [12] which some of these organic compounds have been used as organic corrosion inhibitors for metals [13].

Adsorption of organic molecules may be explained by the presence of an oxygen atom (a hetroatom), $\pi$ electron of aromatic rings and electron donating groups. The hetro-atoms such as oxygen are the major adsorption center in organic compounds for its interaction with the metal surface [14]. The adsorption can also occur via electrostatic interaction between a negatively charged surface, which is provided by a specifically adsorbed anion $\left(\mathrm{Cl}^{-}\right)$on iron, and the positive charge of the inhibitor [15]

\subsection{Electrochemical impedance measurements (EIS)}

The Nyquist representation of the impedance behavior of steel in $1 \mathrm{M} \mathrm{HCl}$ with and without the juice is shown in Fig. 2. The existence of a single semi circle showed the presence of single charge transfer process during corrosion which was unaffected by the presence of inhibitor molecules [11].

The slightly depressed nature of the semi circle, which has the center below the x-axis, is the characteristics for solid electrodes and such frequency dispersion has been attributed to roughness and other inhomogeneties of the solid electrode [16]. The charge transfer resistance $\left(\mathrm{R}_{\mathrm{ct}}\right)$ and the interfacial double layer capacitance (CPE) values were derived by using the equivalent circuit shown in Fig. 3. The equivalent circuit elements calculated by Zview fitting program are given in Table 2. The value of $\mathrm{R}_{\mathrm{ct}}$ is increased from 32.8 to $448.8 \Omega \mathrm{cm}^{2}$ and corresponding CPE value decreased from $7.84 \times 10^{-5}$ to $2.50 \times 10^{-5} \mu \mathrm{F} \mathrm{cm}^{-2}$ without and in the presence of fruit juice. There is relatively good agreement between the polarization resistances, obtained from both electrochemical methods.

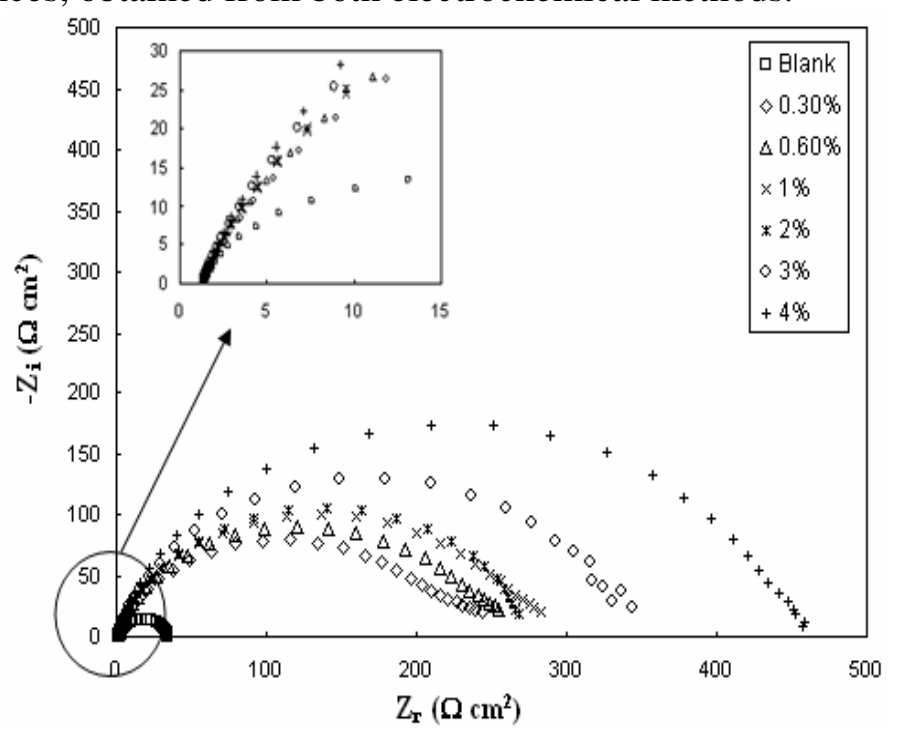

Figure 2. Nyquist diagrams of steel corrosion in $1 \mathrm{M} \mathrm{HCl}$ solution with and without the juice at $25^{\circ} \mathrm{C}$. 


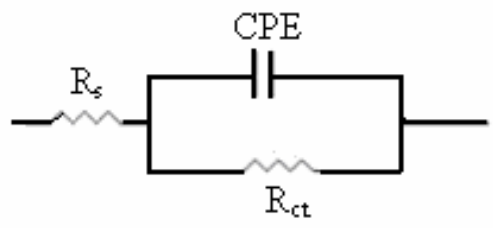

Figure 3. Equivalent circuit for steel in $\mathrm{HCl}$.

Table 2. Impedance parameters obtained by Zview fitting program in $1 \mathrm{M} \mathrm{HCl}$ solution with and without the juice.

\begin{tabular}{|c|c|c|c|c|}
\hline $\begin{array}{c}\text { Inhibitor } \\
\text { concentration } \\
(\mathbf{V} / \mathbf{V} \%)\end{array}$ & $\begin{array}{c}\mathbf{R}_{\mathbf{s}} \\
\left(\mathbf{\Omega} \mathbf{~ c m}^{\mathbf{2}}\right)\end{array}$ & $\begin{array}{c}\mathbf{R}_{\mathbf{c t}} \\
\left(\mathbf{\Omega} \mathbf{~ m}^{2}\right)\end{array}$ & $\mathbf{C P E}\left(\boldsymbol{\mu} \mathbf{F} \mathbf{c m}^{-2}\right)$ & IE \% \\
\hline $\mathbf{0}$ & 1.4 & 32.8 & $7.84 \times 10^{-5}$ & - \\
\hline $\mathbf{0 . 3}$ & 1.3 & 223.3 & $2.34 \times 10^{-5}$ & 85.17 \\
\hline $\mathbf{0 . 6}$ & 1.5 & 250.3 & $2.16 \times 10^{-5}$ & 86.89 \\
\hline $\mathbf{1}$ & 0.1 & 266.4 & $2.67 \times 10^{-5}$ & 87.68 \\
\hline $\mathbf{2}$ & 0.2 & 274.3 & $2.26 \times 10^{-5}$ & 88.04 \\
\hline $\mathbf{3}$ & 0.1 & 336.5 & $2.79 \times 10^{-5}$ & 90.25 \\
\hline $\mathbf{4}$ & 0.5 & 448.8 & $2.50 \times 10^{-5}$ & 92.69 \\
\hline
\end{tabular}

\subsection{Effect of temperature}

The effect of temperature on the inhibition efficiency of steel in $1 \mathrm{M} \mathrm{HCl}$ containing $4 \mathrm{v} / \mathrm{v} \%$ of inhibitor at temperature ranging from 25 to $85^{\circ} \mathrm{C}$ and also in the absence of inhibitor, after 30 minutes immersion, was obtained with both electrochemical methods. Polarization and Nyquist plots are represented in Figures 4 and 5, respectively. The deduced parameters from polarization and EIS measurements are given in Table 3. The corrosion inhibition effect of Prunus cerasus juice decreases when the temperature rises to $85^{\circ} \mathrm{C}$. This may be explained due to the structure degradation of existing organic compounds in the inhibitor. Thermal degradation of Prunus cerasus's anthocyanine was previously reported [17].

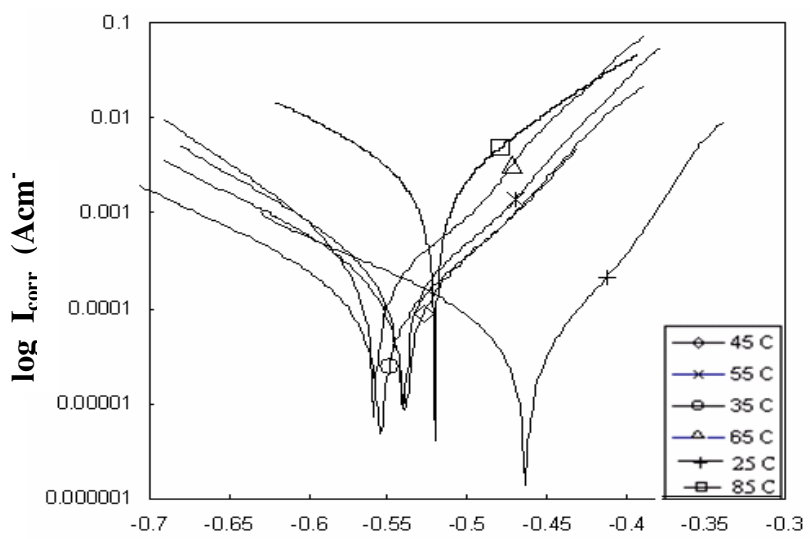

Figure 4. Polarization curves of steel corr $\quad$ E(V vs $\mathrm{HCl}$ solution with $4 \%$ v/v juice at different temperatures. 


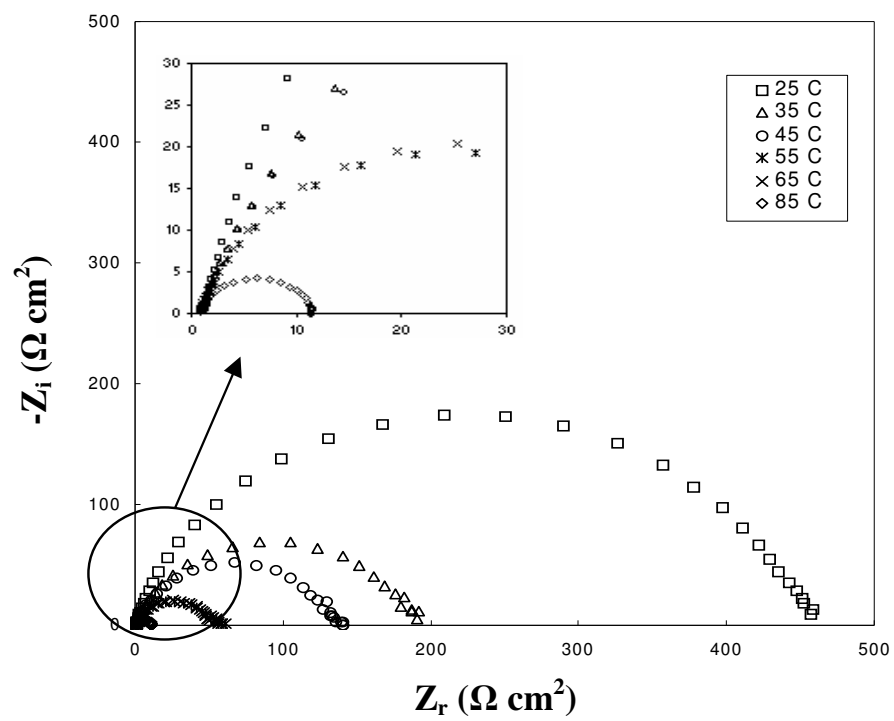

Figure 5. Nyquist diagrams of steel corrosion in $1 \mathrm{M} \mathrm{HCl}$ solution with $4 \%$ v/v juice at different temperatures

Table 3. Effect of temperature on the corrosion inhibition by the juice $(4 \% \mathrm{v} / \mathrm{v})$ obtained from polarization and EIS measurements.

\begin{tabular}{|c|c|c|c|c|c|}
\hline & \multicolumn{5}{|c|}{ Polarization measurements } \\
\hline $\mathrm{Tem} /{ }^{\circ} \mathrm{C}$ & $\begin{array}{c}\mathbf{R}_{\mathrm{p}} \\
\left(\Omega \mathrm{cm}^{2}\right)\end{array}$ & $\begin{array}{c}\mathbf{b}_{\mathrm{a}} \\
(\mathrm{mV} / \mathrm{dec})\end{array}$ & $\begin{array}{c}\mathbf{b}_{\mathrm{c}} \\
(\mathrm{mV} / \mathrm{dec})\end{array}$ & $\begin{array}{c}\mathbf{I}_{\text {corr }} \\
\left(\mathrm{Acm}^{-2}\right)\end{array}$ & IE\% \\
\hline 25 & 471.7 & 62 & 92 & $3.39 \times 10^{-5}$ & 94.10 \\
\hline 35 & 215.6 & 99 & 99 & $1.01 \times 10^{-4}$ & 92.05 \\
\hline 45 & 137.3 & 93 & 90 & $1.45 \times 10^{-4}$ & 93.01 \\
\hline 55 & 99.0 & 90 & 96 & $2.04 \times 10^{-4}$ & 96.69 \\
\hline 65 & 77.1 & 101 & 76 & $2.44 \times 10^{-4}$ & 96.44 \\
\hline \multirow[t]{2}{*}{85} & 10.1 & 104 & 126 & $2.44 \times 10^{-3}$ & 81.02 \\
\hline & \multicolumn{5}{|c|}{ EIS measurements } \\
\hline $\mathrm{Tem} /{ }^{\circ} \mathrm{C}$ & \multicolumn{2}{|c|}{$\begin{array}{c}\mathbf{R}_{\mathrm{ct}} \\
\left(\Omega \mathrm{cm}^{2}\right)\end{array}$} & $\begin{array}{c}\mathrm{CPE} \\
\left(\mu \mathrm{Fcm}^{-2}\right)\end{array}$ & $\mathbf{n}$ & IE\% \\
\hline 25 & \multicolumn{2}{|c|}{448.8} & $2.50 \times 10^{-5}$ & 0.8454 & 92.69 \\
\hline 35 & \multicolumn{2}{|c|}{184.7} & $1.62 \times 10^{-5}$ & 0.8169 & 92.37 \\
\hline 45 & \multicolumn{2}{|c|}{129.3} & $2.77 \times 10^{-5}$ & 0.8560 & 94.39 \\
\hline 55 & \multicolumn{2}{|c|}{63.1} & $5.30 \times 10^{-5}$ & 0.8396 & 95.51 \\
\hline 65 & \multicolumn{2}{|c|}{51.1} & $6.36 \times 10^{-5}$ & 0.8560 & 94.15 \\
\hline 85 & \multicolumn{2}{|c|}{11.0} & $6.42 \times 10^{-5}$ & 0.8339 & 84.29 \\
\hline
\end{tabular}




\section{CONCLUSIONS}

Results obtained from both electrochemical methods showed that the Prunus cerasus juice acts as an inhibitor for corrosion of steel in hydrochloric acid media. Corrosion inhibition action of Prunus cerasus juice increased as its concentration increases. Inhibition of steel in $\mathrm{HCl}$ solution by Prunus cerasus juice is attributed to adsorption of the phytochemical compounds in this juice. The reduction of corrosion inhibition efficiencies by increasing the temperature, may be due to thermal degradation of its organic content especially degradation of anthocyanine pigments.

\section{References}

1. H. Ashassi-Sorkhabi, M. R. Majidi and K. Seyyedi, Applied Surface Science,225(2004)176

2. A.Y. El-Etre, Corrosion Science,45(2003)2485

3. A.Y. El-Etre, Corrosion Science, 40 (1998)1845

4. H. Ashassi-Sorkhabi, Z. Ghasemi and D. Seifzadeh, Applied Surface Science, 249 (2005)408

5. M. Bethencourt, F.J. Botana, J.J. Calvino and M. Marcos,Corrosion Science,40(1998)1803

6. S. Virtanen, M.B. Ives, G.I. Sproule, P. Schmuki and M.J. Graham, Corrosion Science,39(1997)1897.

7. $\quad$ B. Davó and J.J. de Damborenea, Electrochimica Acta,49(2004)4957

8. A. Aballe, M. Bethencourt, F. J. Botana and M. Marcos, Journal of Alloys and Compounds, 323-324(2001)855

9. K. C. Emregül and M. Hayval1, Materials Chemistry and Physics,83(2004)209

10. S.A. Abd El-Maksoud, Electrochimica Acta,49(2004) 4205

11. H. Ashassi-Sorkhabi, B. Shaabani and D. Seifzadeh, Electrochimica Acta,50(2005) 3446

12. S.D. Casini and R. Bagger-Jorgensen, Cross Flow Filtration of Fruit Juice, (www.mst.dk/udgiv/Publications/2000/87-7944-134-3/html/kap02_eng.htm)

13. E.S. Ferreira, C. Giacomelli, F.C. Giacomelli, A. Spinelli; Materials Chemistry and Physics, 83 (2004)129

14. E. Rocca, C. Rapin and F. Mirambet, Corrosion Science,46(2004)653

15. K. Tebbji, H. Oudda, B. Hammouti, M. Benkaddour, M. El Kodadi and A. Ramdani, Colloids and Surfaces A: Physicochem. Eng. Aspects259(2005)143

16. H. Ashassi-Sorkhabi, B. Shabani, B. Aligholipour and D. Seifzadeh, Applied Surface Science(2005) in press.

17. M. J. Rein Thesis, University of Helsinki, Department of Applied Chemistry and Microbiology (2005).

(C) 2006 by ESG (www.electrochemsci.org) 